[15] Chernov, V. G., Pavlenko, M. A., Tymochko, A. I., Svistunov, D. Yu., Koroluk, N. A. (2014). Method of forming set individual test tasks for assessment level of operator training acs during simulator training. Systemy upravlinnia, navihatsiyi ta zviazku, 2, 75-80.

[16] Knyazev, V. A. (2005). Tekhnologiya ocenki urovnya deyatel'nosti operatorov v chelovekomashinnyh sistemah. Moscow, 59.

[17] SHana, M. (2014). Avtomatizirovannaya informacionnaya sistema adaptivnogo obucheniya na osnove kompetentnostnogo podhoda. Nal'chik, 182.

[18] Kobzar', A. I. (2006). Prikladnaya matematicheskaya statistika. Moscow: Fizmatlit, 816.

[19] Lebedyk, M. P. (2003). Tekhnolohiya atestatsiyi tsilisnoho rozvytku osobystosti na osnovi otsinok sotsialnoi zrilosti uchasnykiv pedahohichnoho protsesu. Poltava: RVV PUSKU, 305.

[20] ISO/TR 18529:2000. Ergonomics - Ergonomics of human-system interaction - Human-centred lifecycle process descriptions (2000). International Organization for Standardization, 28.

\title{
PROACTIVE DEVELOPMENT OF ORGANIZATIONAL STRUCTURE OF TERRITORIAL DEVELOPMENT PROJECT WITH USING BI-ADAPTIVITY
}

\author{
Alexander Timinsky \\ Department of management technologies \\ Taras Shevchenko National University of Kyiv \\ 64/13 Volodymyrska str., Kyiv, Ukraine, 01601 \\ timin@ukr.net \\ Illia Marushchak \\ Department of Business Administration and Project Management \\ University of Economics and Law «KROK» \\ 30-32 Tabirna str., Kyiv, Ukraine, 03113 \\ ilya.old@meta.ua
}

\begin{abstract}
The article presents the scientific task of developing models and methods of proactive development of the organizational structure of territorial development projects using bi-adaptivity. Literary sources are analyzed. There are two types of organizational structures - the organizational structure of the territorial development project and the organizational structure of the territorial network, created in the project. The similarity of such structures is noted. The aspects of the organizational structure, for which it is necessary to develop models of proactive development, are selected and analyzed. This is the entrepreneurial form of the territorial network, the type of organizational structure and the system of communications of the organizational structure of the territorial network with the organizational structure of the parent enterprise. The concept of the gradient of the territorial development of the industries has been introduced, its definition has been given. The method of proactive development of the organizational structure in the project of territorial development is proposed. The content of the method of configuring the bi-adaptive system for the appearance of new types of projects is determined. The indicated results extend the scientific tools of project and program management.
\end{abstract}

Keywords: proactivity, bi-adaptivity, territorial development project, organizational structure.

\section{Introduction}

The development of enterprises and organizations in the current turbulent environment involves active project activities. In this regard, enterprises are forced to become project-oriented and implement development projects. One of the most important classes of such projects is the projects of territorial expansion related to the opening of new branches, the development of a network of institutions (representations) and the provision of organizational (commercial) presence 
in other territories. As part of such activities, it is advisable to apply the scientific tools of project management to plan, organize, implement, monitor and control the relevant projects. This requires the development of the organizational structure of the project and the organizational structure of the future territorial network. Another aspect, which requires analysis of territorial development projects - the interaction of project and project management system of company (organization), which implements the project, with its operating system management. Consideration of this circle of questions is devoted to this article.

\section{Literature review and problem statement}

The construction of the system for the management of the territorial development project should be based on internationally recognized project management standards - PMBOK [1], PRINCE2 [2], P2M [3] and others [4-7]. In these standards, in particular, the issue of organizational structures is considered, typical organizational structures are presented, their characteristics are given. However, international standards are universal and not oriented to a certain type of projects. Therefore, for use in territorial development projects, they require rethinking. Management systems for such projects should take into account both the standards and the specifics of the territorial development projects $[8,9]$. In particular, the fact that projects of this type adds a new, territorial dimension to the project activity. It is also necessary to consider the connection of such projects with the strategy of organizational development [10-13]. At the same time, the project-oriented enterprise during its activity should accumulate the good practices. Therefore, it is necessary to apply models of its effective use [14]. Although territorial development projects have already been considered as a separate type of project [15-17], studies do not adequately cover the development of organizational structures within such projects, nor does the development of a bi-adaptive system management of project-oriented enterprises in the implementation of these types of projects.

\section{Materials and Methods}

The basis of this study is the authors' work in the field of territorial development projects [15-17] and the construction of bi-adaptive management systems for project-oriented enterprises [18-20]. Initial materials of the research served as data obtained during the implementation of the project development of territorial branches of the international medical company.

The main methods of research are methods of analysis and synthesis, structural analysis and decomposition. Specific research methods are taken from project management standards [1-7].

\section{Development of organizational structure}

A management entity that develops its territorial network may be an industrial, communal or other enterprise, company, institution or organization of another form. For generalization, let's call the subject of enterprise management.

The territorial network of the enterprise should be guided by some organizational structure, which should be created in the project of territorial development (let's name it the target structure).

The organizational structure of the territorial development project should reproduce the target structure in the miniature, be its prototype. Therefore, these structures should be considered together.

The created organizational structure (target structure) has several significant aspects (dimensions), about which it is necessary to develop models of proactive development. Let's highlight these aspects:

- entrepreneurial form of the territorial network;

- the type of organizational structure (based on the typology let's take the model of organizational structures identified in the sixth edition of PMBOK [1]);

- system of communications of the organizational structure of the territorial network with the organizational structure of the parent company (head office).

Let's consider each aspect in turn.

1. The entrepreneurial form of the territorial network.

Depending on the type of activity carried out by the company, the territorial network may include: 
- representation of the limited liability company;

- branches of the enterprise with full set of functional enterprise and extended powers;

- production capacity;

- logistic capacities (warehouse, transport logistics);

- trade network and more.

In addition, the territorial presence of the enterprise may be subject to change. It can evolve from mere representation to a complex territorial representation with offices, production, trade and logistics networks. In view of this, the proactive development of the organizational structure should include the target structure of the territorial units for future periods.

2. Type of organizational structure.

Let's consider eligibility for territorial development projects of the organizational structure models identified in the sixth edition of the PMBOK [1], analyzing each of them.

Organic or simple organizational structure. It is characterized by a small number of staff and flexible management. Used mainly in small companies, when creating business, new business lines and in startups. Can be used in the territorial development project at its initial stages and for territorial departments in non-large-scale territories.

Functional (centralized) organizational structure. Characterized by a rigid hierarchy, with the hierarchy clearly distinguishing functions performed by the enterprise. Each function has its own organizational vertical. Can be used in the territorial development project at the mature stages of the development of the target structure.

Multidivisional the organizational structure (functions in each unit can be duplicated almost without centralization). Characterized by the recurrence of a functional in each territorial unit. It can be used in the territorial development project to create a production territorial network - a network of production facilities in each territory.

Weak matrix organizational structure. The functional structure is accompanied by a project coordination function assigned to an individual employee. In territorial development projects it is inappropriate to use.

With a balanced matrix of organizational structure. Characterized by the presence of a project manager as a separate post (this post is added to the functional structure, after which the structure becomes a balanced matrix). Can be used in the territorial development project for the central office.

Strong matrix organizational structure. Characterized by the presence in the structure of the unit, which includes the heads of individual projects. Also, it can be used in the regional development project from the central office in case when the central office implements several similar projects.

Organizational structure with a focus on the project. It is characterized by the creation of a separate structure for the implementation of the project. Since such a structure does not presuppose the existence of a parent organization and its interaction with it, it is inappropriate to use it in the territorial development project.

Virtual organizational structure (from the structure of the network with nodes at points of contact with other people). It is characterized by the fact that the project team works in a virtual environment (using the Internet or other remote communication methods). Can be used in the territorial development project by the decision of management of the central office of the enterprise. However, as the created territorial structure (as a target structure) can't be considered.

Hybrid organizational structure. This structure is a combination of previous structures in one enterprise. It can be used by the central office in its activities, but is poorly suited for territorial development projects and for the target structure, especially at the initial stages of its development.

Project Management Office (office or project management, program or portfolio of projects). May be a separate structure of the parent company that implements the project activity. According to the decision of the central office such structure (if it exists at the enterprise) can manage the territorial development project. But it can't be a prototype of the target structure. 
The proactive development of the type of organizational structure (both the project and the target structure) should include a model (or system of rules) for choosing the type of structure for future periods, depending on a certain list of influential factors.

3. Communication system of the target structure with the head office.

The communication system should include the following components:

- regulations, policies and procedures for communications;

- means of communication (including IT solutions);

- consolidation of organizational responsibility for the system of communications in general;

- communication system development strategy;

- database of communications;

- rules and norms of communications.

The proactive development of the communications system should include a model (or system of rules) for choosing new (or improving existing) solutions for the components of the system in the future periods.

Let's highlight the main parameters of the organizational structure of the territorial development project, which determine its essential characteristics (Table 1).

Table 1

Characteristics of the organizational structure of the territorial development project

\begin{tabular}{cccc}
\hline No. & Sphere & Characteristic & Unit \\
\hline 1 & The organizational structure & Number of team members & People \\
2 & The organizational structure & Number of levels of structure & Numeric \\
3 & The organizational structure & Maximum number of subordinates in unit managers & Numeric \\
4 & Management processes & Number of business processes & For one member of the team \\
5 & Management processes & Number of business processes that must be & Numeric \\
6 & Management processes & Number of subprojects (for example, branches to & Numeric \\
7 & Communication system & be opened) & Number per week (month)
\end{tabular}

Consequently, considering the development of the organizational structure in the territorial development project, it is necessary to take into account the development of three aspects (form, type, communication). In order to create a proactive tool for the development of the organizational structure, a system should be proposed for the persons who will make decisions within the project.

The decision support system (DSS) for the management of the territorial development project will start to be developed for two aspects of the project - organizational structure of the project and the created organizational structure of the territorial network (target structure) .

Such a DSS, presented as a black box model, will have some input on the assessment of the external and internal environment of the project implementation, and on the output - the proposed decision on the recommended organizational structure.

To formalize the DSS, let's propose a decision-making method based on the gradient of territorial development of the industry, by proposing the appropriate definition.

Definition 1. Gradient of the territorial development of the industry - an indicator that define the dynamics of the industry in some areas (of the country and/or other countries), with administrative, geographical or others limits.

When calculating the gradient of territorial development (it is supposed to carry out the calculation by the method of expert assessments) it is proposed to take into account the following list of factors:

- the scale of the industry in the structure of the territory's economy;

- the dynamics of industry development (the scale of the industry in comparison with the previous periods of time); 
- favorable investment climate;

- the dynamics of innovation in the industry (accelerating or slowing down the introduction of innovations);

- entrance barriers for penetration into the industry.

Each of the factors should be included in the overall assessment of the gradient with its own weight. Weight must also be determined expertly.

Sequence of the method realization of proactive development of the organizational structure in the project of the territorial development is the following:

- definition of the forecast period;

- assessment of the gradient of territorial development of the industry;

- evaluation of assets of central office processes;

- definition of the list of territories for expansion of the enterprise (within the project scope);

- definition (based on the previous indicators) of feasible options of three elements of the organizational structure (form, type, communication);

- evaluation of their advantages and disadvantages;

- development of recommendations for implementation;

- development of recommendations for the further development of the organizational structure.

\section{Use of bi-adaptivity}

The territorial development project is implemented in project-oriented enterprises. These are enterprises that carry out parallel operational and project activities. Consequently, in such enterprises there is a subsystem of operational management and subsystem of project management. An urgent task of efficiently coordinated work of these subsystems arises. For this purpose, the concept of bi-adaptivity is used and the direction of bi-adaptive systems is developed [18-20].

Definition 2. Bi-adaptive system - the system that operates in project-oriented enterprises. The main task of the bi-adaptive system is adaptation of the project subsystem to changes in the operating subsystem, as well as adaptation of the operating subsystem to changes in the project subsystem.

The bi-adaptive system should take into account the interaction of the organizational structure of the project with the organizational structure of the parent enterprise. Therefore, by analogy with Table 1, let's define the main parameters of the organizational structure of the parent enterprise, which determine its essential characteristics (Table 2).

Table 2

Characteristics of the organizational structure of the parent enterprise

\begin{tabular}{cccc}
\hline No. & Sphere & Characteristic & Unit \\
\hline 1 & The organizational structure & Number of personnel of the enterprise & People \\
2 & The organizational structure & Number of levels of structure at the enterprise & Numeric \\
3 & The organizational structure & Maximum number of subordinates in unit executives & Numeric \\
4 & Management processes & Number of business processes of the enterprise & Numeric \\
5 & Management processes & Number of business processes of the enterprise & For one employee \\
6 & Management processes & Number of business processes to be implemented in & Numeric \\
7 & Management processes & pumber of business processes that must be imple- & For one employee \\
8 & Communication system & mented in parallel & Number per week (month) \\
9 & Communication system & Number of weekly reports & For one employee
\end{tabular}


Territorial development projects are characterized by certain specificity. Therefore, their implementation affects the bi-adaptive system. As a result, the bi-adaptive system of the parent company should undergo changes (correction, expansion or improvement).

Let's determine the direction of the following changes:

- inclusion in the bi-adaptive system of territorial dimension;

- inclusion in the bi-adaptive system of new types of organizational structures that appeared in project management (in the sixth edition of the PMBOK);

- inclusion in the bi-adaptive system the gradient of the territorial development of the industry;

- correction of methods of bi-adaptive management due to expansion of new models.

Links between the organizational structure of the territorial development project and the organizational structure of the parent enterprise should be be-adaptive (Fig. 1).

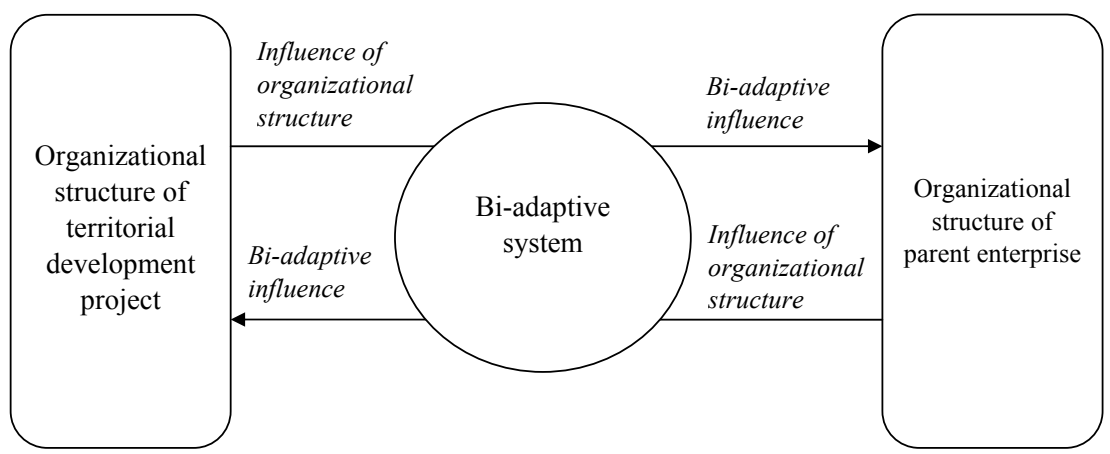

Fig. 1. Bi-adaptive interactions between organizational structures

Consequently, it can be assumed that the emergence of new types of projects implemented by the enterprise may require correction of the bi-adaptive system and its parameters. Let's propose the content of the method of setting up a bi-adaptive system for the appearance of new types of projects:

- analysis of new trends in operational and project management;

- analysis of the impact of the project on the enterprise management system;

- analysis of the need for correction of the bi-adaptive system;

- choosing project parameters that affect the bi-adaptive system;

- select the parameters of the bi-adaptive system to be changed;

- generation of parameter change model;

- setting the parameter change model (testing the bi-adaptive system);

- fixation of final changes of the bi-adaptive system.

Based on this method, slightly modifying it may be suggested method for bi-adaptive scaffolding systems to new business lines (or other types of changes) operating subsystem project-oriented enterprises.

\section{Results and discussion}

Let's conduct a SWOT analysis of the proposed approaches to the proactive development of the organizational structure of territorial development projects using bi-adaptivity. Let's highlight their strengths and weaknesses, opportunities and threats.

Strengths include systemicity, complexity and flexibility.

The weaknesses include the need for adaptation for each new type of project to be implemented by the project-oriented enterprise.

Opportunities include the ability to be widespread in most substantive areas of application.

Threats include the appearance of systemic changes both in operational and project management subsystems, which can fundamentally affect both the territorial development projects and the bi-adaptive system of management of project-oriented enterprises. This may require no adjustment, but a complete revision of management approaches. 


\section{Conclusions}

The combination of the principles of proactivity and bi-adaptivity can improve the system of project management of territorial development of project-oriented enterprises. In such projects, one of the essential aspects is the organizational structure. What is important is that it is necessary to develop not only the organizational structure of the project itself, but also the organizational structure of the territorial network that created in the project. These organizational structures are interconnected and somewhat similar. And so for them a general scientific toolkit can be developed. The article highlights aspects of the development of the organizational structure, defines the gradient of the territorial development of the industries, and proposes a method for the proactive development of the organizational structure in the territorial development project, the content of the method of tuning the bi-adaptive system for the appearance of new types of projects is determined. The indicated results extend the scientific tools of project and program management.

\section{References}

[1] A Guide to the Project Management Body of Knowledge (PMBOK® Guide) (2017). USA, PMI, 537.

[2] OGC (Office of Government Commerce). Managing Successful Projects with PRINCE2 (2009). TSO (The Stationery Office), Printed in the United Kingdom for the Stationery Office, 327.

[3] Bushuyev, S. D. (2009). Guidelines for management of innovative projects and programs: Vol. 1, Version 1.2. Naukovyi Svit, Kyiv, 173.

[4] ISO 21500:2012. Guidance on project management (2012). Project Committee ISO/PC 236, 36.

[5] IPMA Project Excellence Baseline (IPMA PEB) for Achieving Excellence in Projects and Programmes. Version 1.0 (2016). International Project Management Association. Amsterdam, 112.

[6] The GPM P5 Standard for Sustainability in Project Management. Available at: https://www. researchgate.net/publication/282816191_The_GPM_P5_Standard_for_Sustainability_in_Project_Management

[7] Oracle ${ }^{\circledR}$ Project Management User Guide. Release 12.2. (2013). Part No. E49016-01. Available at: https://docs.oracle.com/cd/V39571_02/current/acrobat/122pjtug.pdf

[8] Goncharuk, V. (2011) Branch networks: construction practice. Available at: http://www.marketing.spb.ru/lib-mm/sales/affiliated_chain.htm

[9] Sorokina, T. (2007). Branch Network: Development and Management. Saint Petersburg, 352.

[10] Deineka, O. G., Kultenko V. V. (2013). System of planning of organizational and technical development at the enterprise. Collection of scientific works UkrSURT, 140, 121-124.

[11] Mamonova, V. V., Kuts, Yu. O., Solder, O. V. (Eds.) (2014). Formation of territorial clusters as an instrument of regional development. Kyiv, 52.

[12] Legenko, Yu. V., Evtukhova, T. I., Mishchenko, R. I. (2013). Development projects management. Kyiv: Ukrtechinform, 291.

[13] Burik, Z. M. (2008). Strategic planning and programmatic management of regional development. Theory and practice of public administration, 3, 140-146.

[14] Voitenko, O. S. (2006). Cognitive models of program management based on the use of best practices. Project Management and Production Development, 3 (19), 37-41.

[15] Marushchak, I. (2018). Models of the project of territorial development of project-oriented organizations with principle of valuable approach. Management of Development of Complex Systems, 34, 51-57.

[16] Marushchak, I. (2017). Analysis of approaches to the preparation and implementation of the project of development of the network of regional branches of the medical holding. Bulletin of Lviv State University of Life Safety, 16, 60-67.

[17] Marushchak, I. O. (2018). Selection of effective organizational structure of the territorial development project of the project-oriented organization. Proceedings of the XV International Conference "Project Management in Society Development." Theme: "Project Management in Transition to the behavioral economy". Kyiv: KNUCA, 137-139.

[18] Teslya, Y., Timinsky, A. (2015). Analysis of approaches to constructing bi-adaptive management systems of project-oriented enterprises. Eastern-European Journal of Enterprise Technologies, 2 (3 (74)), 38-42. doi: https://doi.org/10.15587/1729-4061.2015.39988 
[19] Timinsky, A. G. (2016). The conceptual model of bi-adaptive control system of project-oriented enterprise. Scientific enquiry in the contemporary world: theoretical basics and innovative approach. San Francisco, 289-292.

[20] Timinsky, A. G. (2017). Models of mutual impact of project subsystems and operating subsystems of project-oriented enterprises. Management of Development of Complex Systems, 29, 110-115.

\title{
METHOD FOR DETECTING ANOMALOUS STATES OF A CONTROL OBJECT IN INFORMATION SYSTEMS BASED ON THE ANALYSIS OF TEMPORAL DATA AND KNOWLEDGE
}

\author{
Oksana Chala \\ Department of Information Control Systems \\ Kharkiv National University of Radio Electronics \\ 16 Nauka ave., Kharkiv, Ukraine, 61166 \\ oksana.chala@nure.ua
}

\begin{abstract}
The problem of finding the anomalous states of the control object in the management information system under conditions of uncertainty caused by the incompleteness of knowledge about this object is considered. The method of classifying the current state of the control object in real time, allowing to identify the current anomalous state. The method uses temporal data and knowledge. Data is represented by sequences of events with timestamps. Knowledge is represented as weighted temporal rules and constraints. The method includes the following key phases: the formation of sequences of logical facts; selection of temporal rules and constraints; classification based on a comparison of rules and constraints. Logical facts are represented as predicates on event attributes and reflect the state of the control object. Logical rules define valid sequences of logical facts. Performing a classification by successive comparisons of constraints and weights of the rules makes it possible to more effectively identify the anomalous state since the comparison of the constraints reduces the subset of facts comparing to the current state. The method creates conditions for improving management efficiency in the context of incomplete information on the state of a complex object by using logical inference in knowledge bases for anomalous states of such control objects.
\end{abstract}

Keywords: anomalies, temporal rule, temporal knowledge base, management information system, event attributes.

\section{Introduction}

The information management system is a human-machine system that designed to solve the tasks of managing the production and business activities of an enterprise based on automated collection, transmission and processing of information about the activities of this enterprise [1]. The tasks of enterprise management are implemented through a sequence of actions that allows to achieve planned results in terms of the impact of both internal and external environment of the enterprise $[2,3]$.

In practice, these tasks are performed under conditions of uncertainty at the level of the control object as a whole or of its individual components. Uncertainty of the second type is caused by incomplete information about the values of individual parameters of the control object. The uncertainty of the first type reflects the incompleteness of information about the control object in general.

In solving problems of control under conditions of the uncertainty of the second type, a priori knowledge of the subject area and traditional, usually deterministic mathematical models of the control object are used [4].

When solving management problems under conditions of the uncertainty of the second type, it is relevant to use an expert knowledge base reflecting the experience of the company's personnel [4]. This knowledge base formed or through experts' interrogation [5], or by monitoring the opera- 